\title{
Hepatitis B Virus Genotype $H$ and Environmental Factors Associated to the Low Prevalence of Hepatocellular Carcinoma in Mexico
}

\author{
Sonia Roman, Nora Alma Fierro, Laura E. Moreno-Luna, Arturo Panduro \\ Department of Molecular Biology in Medicine, Hospital Civil de Guadalajara, Fray Antonio Alcalde, Centro Universitario de \\ Ciencias de la Salud, Universidad de Guadalajara, Guadalajara, Mexico. \\ Email: biomomed@cencar.udg.mx, apanduro@prodigy.net.mx
}

Received December $12^{\text {th }}, 2012$; revised January $14^{\text {th }}, 2013$; accepted January $23^{\text {rd }}, 2013$

\begin{abstract}
Purpose: Hepatocellular carcinoma (HCC) is a leading health problem worldwide. Any agent causing chronic liver damage and cirrhosis is a risk factor for HCC. Genetic and environmental factors may be responsible for regional variations in the occurrence of HCC worldwide. The aim of this review was to describe the risk factors that may be contributing to low prevalence of HCC in the Mexican population. Methods: An electronic systematic search was conducted in four databases to retrieve studies on hepatocellular carcinoma in Mexico. Results: Eighteen publications gave a total of 1042 HCC cases with a percentage that ranged from $0.25 \%$ to $1.87 \%$. Cirrhosis was registered in 7 studies while the main etiologies were: HCV (66\%), HBV (11\%) and alcoholism (6.6\%). Conclusions: In the last 50 years, the studies performed in Mexico have shown a very low incidence and/or mortality rate of HCC. These findings contrast from those reported in high endemic regions, such as Asia, where viral hepatitis and HCC are prevalent. One significant difference is the predominance of HBV genotype $\mathrm{H}$ in Mexico and HBV/B and C in Asia. In Mexico, high endemic areas of HBV infection have been detected, mainly among the native population; however, infection seems to resolve very quickly, due to a prominent immunological response among the population. Other factors are that patients with liver cirrhosis die prematurely before that HCC can be detected. Furthermore, an environmental factor that may exert a protective effect against HCC, in spite of the high consumption of potentially aflatoxin-contaminated food products, is the neutralization of these substances by alkaline treatment. This study shows that genetic and environmental factors associated to HCC among the Mexican population are different from others reported worldwide.
\end{abstract}

Keywords: HBV Genotype H; HCV; Alcoholism; Aflatoxins; Cirrhosis; Nixtamalization

\section{Introduction}

Hepatitis B virus (HBV) infection is a serious worldwide healthcare problem. It may be spread by horizontal transmission of the virus through parenteral exposure to infectious blood or body fluids such as semen and vaginal fluids. Vertical transmission is caused by perinatal exposure from infected mother-to-infant [1].

The prevalences of HBV infection in populations vary according to the incidence and age of the primary infection. In the endemic regions of the world, vertical transmission of HBV infection is most prevalent among infants and children, while in the low-risk regions, adolescents and adults are mainly infected by horizontal transmission [1].

The severity and outcomes of chronic liver disease such as liver cirrhosis and hepatocellular carcinoma (HCC) may depend on a complicated viral-host-environment interaction. Thus, viral factors such as HBV genotypes as well as the host/ethnic immune response may play an important role, whereas, environmental factors such as the use of alcohol and exposure to aflatoxins are also involved [2-4].

Hepatocellular carcinoma (HCC) is a common cancer worldwide, responsible for approximately $6 \%$ of all new cases of human cancer (fifth cause in men, and eight cause in women), and for one million deaths/year worldwide [1-4]. The burden of HCC disease is reported as incidence, prevalence or mortality rates, all of which can be subject to significant uncertainties [5]. However, prevalence and incidence are often very similar since HCC almost always kills the patient within 2 or 3 years. The age-adjusted incidence rate (AAIR) serves to compare the frequency of HCC among different population sizes normalized by 100,000 inhabitants. Accordingly, in regions with high risk for HCC, the AAIR ranges from 27.6 to 36.6 per 100,000 in men, in Eastern Asia; 20.8 - 
31.1/100,000 in Middle Africa and 30 - 48/100,000 in some Western African countries. In contrast, in the lowrisk regions, such as Northern Europe, Australia, New Zealand and the Caucasian populations of North and Latin America, the AAIR ranges from 1.5 - 3.0/100,000 $[1,3]$. The board incidence rate of HCC depends largely on differences in ethnicity and the distribution of the putative risk factors confined to each population [1,3].

HCC is a serious health problem associated to cirrhosis in $80 \%$ of the cases. Thus, any agent leading to severe liver damage, and ultimately cirrhosis, should be seen as a risk factor for HCC [6-9]. The main causes of HCC are the same as for cirrhosis: HBV, HCV and alcohol [7]. The exposure to high levels of aflatoxins is another environmental factor that often overlaps with chronic viral hepatitis in certain regions of the world [10,11]. Although HCC has been associated either to HBV or HCV infection in the high-risk populations of Asia [3,7], it is highly likely that host population genetics and environmental factors, other the virus itself may also play a crucial role in the onset and progression of HCC [12].

The prevalence rate of HBV infection among the general Mexican population has been estimated to be $0.3 \%$ (HBsAg serological marker), which has remained stable since 1974 [13]. However, studies carried out among the native Mexicans, Nahuas and Huichol, have revealed a seroprevalence of HBsAg of $6 \%$ and occult hepatitis B infection is prevalent in $14 \%$ of the cases [14]. Regarding HCV infection, the prevalence ranges from $0.4 \%$ to $1.4 \%$ among the general population [15], but recent studies suggest that it may be re-emerging [16]. Furthermore, alcoholic cirrhosis is one of the top leading morbidities with a high mortality rate of over 25,000 deaths/year [17] and several studies suggest a moderate to relatively high consumption of aflatoxin-contaminated cereals [maize/ corn] among the Mexican population [18,19].

Despite the presence of several environmental etiologic factors, the incidence rate of HCC has been reported as low, at least in the western region of Mexico [20], however, this information should not be extrapolated to the rest of the country without detailed analysis. Therefore, the aim of this study was to investigate which risk factors could be contributing to the low frequency of HCC in Mexico and which may differ from those reported in other countries with higher prevalence rates.

\section{Materials and Methods}

\subsection{Data Sources}

A systematic query was conducted to search for publications regarding the existence of hepatocellular carcinoma in Mexico. PubMed

(http://www.ncbi.nlm.nih.gov/pubmed), by means of the
MeSH terms, "hepatocellular carcinoma" and "Mexico" or together with "epidemiology"; Artemisa (http://www.artemisaenlinea.org.mx), Medigrafic (http://www.medigraphic.com) and Imbiomed (http://www.imbiomed.com.mx) were consulted with the terms in Spanish, "carcinoma hepatocelular" or "cancer primario de higado". The electronic search was filtered for publications dated from 1989 (after HCV testing was available) until July 2012. Additional studies were manually identified by back tracking the reference list of the selected papers, which were verified either by PubMed or Google Scholar.

\subsection{Study Selection}

The authors selected either prospective or retrospective epidemiological studies regarding cohort or serial cases of HCC in pediatric or adult Mexican patients. Publications were admitted if cases of HCC were defined as primary liver cancer, whereas other types of liver cancers, such as cholangiocarcinoma or hepatoblastoma were not considered. Case reports were included for descriptive purposes only.

Inclusion criteria were related to sample size, number of HCC cases, frequency rate, patient's demographics, description of histopathological or clinical findings, and recognized environmental factors associated to HCC.

Publications regarding studies on coliangiocarcinoma, hepatoblastoma, metastatic tumors of the liver, treatment modalities, imaging studies, clinical trials or management, experimental animal models, liver transplantation or drug therapy were not included in this review. Also, if study information was insufficient to draw conclusions, the paper was also excluded.

\subsection{Data Extraction and Analysis}

Each author conducted his/her own search by means of the keywords aforementioned. All eligible or excluded publications were cross-checked among all authors, and then read by authors SR and AP. SR conducted the data extraction of accepted studies by enlisting them according to the time interval and registering the following data: sample size, number of HCC cases, reported frequency rate, patient's demographics, description of histopathological or clinical findings, and use of alcohol or aflatoxin exposure. Frequencies were estimated as proportions and expressed as percentages. The extracted data were summarized in tables arranged by the inclusion criteria aforementioned.

A descriptive analysis of quantitative and qualitative results was conducted and then integrated into a comprehensive discussion of the main features of HCC cases in Mexico within each subheading. 


\section{Results and Discussion}

\subsection{Studies}

A total of 132 publications were retrieved by means of the designated keywords, of which 18 of them met the eligibility criterion. Among these, if information was missing, it was marked as "not reported" in the respective table.

\subsection{Demographic and Clinical Data in Mexican HCC Patients}

Among the 18 publications, 20 studies of HCC cases were conducted. The demographic and clinical data of 1042 HCC cases reported from 1953 to 2007 are summarized in Table 1. Subjects were 459 males and $330 \mathrm{fe}-$ males (ratio 1.39 to 1 ) that attended third level medical

Table 1. Summary of relevant data as reported from publications on HCC cases in Mexico.

\begin{tabular}{|c|c|c|c|c|c|c|c|c|c|c|}
\hline No. & Year/Ref. & $\begin{array}{c}\text { Study } \\
\text { Period (years) }\end{array}$ & Study source & $\begin{array}{l}\text { Sample } \\
\text { size }\end{array}$ & $\begin{array}{l}\text { HCC cases } \\
(n)\end{array}$ & $\begin{array}{c}\text { Gender } \\
(M / F)\end{array}$ & $\begin{array}{c}\text { Age } \\
\text { (years) }\end{array}$ & $\begin{array}{l}\text { Hispathological, clinical } \\
\text { and risk factor data }\end{array}$ & $\begin{array}{c}\text { Cirrhotic } \\
\text { cases } n(\%)\end{array}$ & Inst. \\
\hline 1 & $1968,[21]$ & 1953-66 & Autopsy series & 6558 & 30 & $21 / 9$ & $50-60$ & $\begin{array}{c}\text { Post-necrotic } \\
\text { macronuclear pattern }\end{array}$ & $20(66)$ & 1 \\
\hline 2 & $1977,[22]$ & 1966-89 & Necropsy series & 12,556 & 73 & $49 / 24$ & $22-78$ & Alcoholic cirrhosis & $55(75)$ & 2 \\
\hline 3 & 1994, [23] & $1971-90$ & $\begin{array}{l}\text { Prospective series HCC } \\
\text { patients }\end{array}$ & 76 & 64 & $49 / 27$ & $66^{*}$ & $\begin{array}{l}\text { HBV infection markers } \\
(40 \%)\end{array}$ & $61(80)$ & 3 \\
\hline 4 & 1996, [24] & 1985-93 & $\begin{array}{l}\text { Retrospective liver } \\
\text { biopsy series of HCC } \\
\text { patients }\end{array}$ & NR & 21 & $15 / 6$ & NR & $\begin{array}{c}\text { 66\% solid tumors; } \\
\text { AFB1-albumin adducts; } \\
\text { HBV, HCV infection }\end{array}$ & None & 3 \\
\hline 5 & 2007, [25] & $1980-00$ & $\begin{array}{l}\text { Retrospective cohort of } \\
\text { HCV-related } \\
\text { cirrhotic patients with } \\
\text { follow-up }\end{array}$ & 750 & 161 & NR & $52^{* *}$ & $\begin{array}{c}\text { Moderate to severe } \\
\text { histological activity, CP: } \\
\text { 56\% A 37\% B, 7\% C }\end{array}$ & $282(100 \%)$ & 4 \\
\hline \multirow{2}{*}{6} & \multirow{2}{*}{ 2002, [26] } & 1982-91 & \multirow{2}{*}{$\begin{array}{l}\text { Retrospective study in } \\
\text { children }\end{array}$} & NR & 3 & $1 / 2$ & $<15$ & NR & None & 0 \\
\hline & & 1996-99 & & NR & 3 & $2 / 1$ & $<15$ & NR & None & 9 \\
\hline 7 & 1997, [27] & 1985-94 & Cross sectional study & 63 & 58 & $32 / 31$ & $16-87$ & $\begin{array}{l}\text { Associated to liver disease } \\
\text { (56\%), 28\% alcoholic } \\
\text { cirrhosis, O: } 10 \% \text { I, } 70 \% \text { II, } \\
\text { 17\% III }\end{array}$ & None & 4 \\
\hline 8 & 2002, [28] & 1987-01 & Retrospective cohort & 121 & 114 & NR & NR & Fibrolamellar variant 5.6\% & NR & 7 \\
\hline 9 & 2005, [29] & 1990-02 & Retrospective cohort & 130 & 17 & $8 / 9$ & $12-39$ & Fibrolamellar variant 29\% & None & 4 \\
\hline 10 & 2005, [30] & 1990-03 & Retrospective cohort & 174 & 159 & $101 / 58$ & $17-87$ & $\begin{array}{c}\text { Fibrolamellar variant } 8.6 \% \text {, } \\
\text { viral hepatitis }\end{array}$ & NR & 7 \\
\hline 11 & 2004, [31] & 1991-00 & Retrospective cohort & NR & 135 & $77 / 58$ & $16-87$ & $\begin{array}{c}\text { HCV infection; CP: } 19 \% \text { A, } \\
28 \% \text { B,18\% C }\end{array}$ & $89(66)$ & 7 \\
\hline 12 & 2005, [32] & 1992-02 & Retrospective cohort & NR & 127 & $63 / 64$ & $17-82$ & $\begin{array}{c}\text { HCV infection; CP: } 35 \% \text { A, } \\
45 \% \text { B, } 20 \% \text { C }\end{array}$ & NR & 4 \\
\hline 13 & 1999, [20] & 1996-98 & $\begin{array}{l}\text { Prospective cohort } \\
\text { cancer patients }\end{array}$ & 10,025 & 25 & $14 / 11$ & NR & NR & $20(80)$ & 5 \\
\hline 14 & 2009, [33] & 2004-07 & $\begin{array}{l}\text { Prospective, } \\
\text { consecutive cases }\end{array}$ & NR & 47 & $17 / 30$ & $35-68$ & $\begin{array}{c}\text { Criptogenic cirrhosis, HCV } \\
\text { infection, CP: } 15 \% \text { A, } 50 \% \\
\text { B, } 35 \% \text { C }\end{array}$ & $34(72)$ & 2 \\
\hline 15 & 2002, [34] & 2002 & Case report & NA & 1 & $1 / 0$ & 22 & Fibrolamellar variant & None & 8 \\
\hline 16 & 2003, [35] & 2003 & Case report & NA & 1 & $0 / 1$ & 56 & None & None & 8 \\
\hline 17 & 2007, [36] & 2007 & Case report & NA & 1 & $0 / 1$ & 17 & Fibrolamellar variant & None & 4 \\
\hline 18 & 2007, [37] & 2007 & Case report & NA & 2 & $0 / 2$ & $49 / 68$ & $\begin{array}{c}\text { Autoimmune liver } \\
\text { disease and primary biliar } \\
\text { cirrhosis }\end{array}$ & None & 8 \\
\hline
\end{tabular}

No. = Consecutive number. Ref. $=$ Reference. $\mathrm{NR}=$ Not reported. NA = Not applicable, Inst. $=$ Institution: ${ }^{0}$ All public hospitals that attends pediatric cancer patients; ${ }^{1}$ Hospital General, SSA. Mexico City; ${ }^{2}$ Centro Médico Nacional, 20 de Noviembre, ISSSTE, Mexico City; ${ }^{3}$ Hospital Dr. Jose E. Gonzales, Universidad Autónoma de Nuevo León, Monterrey, Nuevo Leon; ${ }^{4}$ Instituto Nacional de Cancerologia, Mexico City; ${ }^{5}$ Centro Médico Nacional de Occidente, Guadalajara, Jalisco; ${ }^{6}$ IMSS, Mexico City; ${ }^{7}$ Instituto Nacional de Ciencias Medicas y Nutrición, Salvador Zubirán, Mexico City; ${ }^{8}$ Médica Sur, Mexico Cty; ${ }^{9}$ Hospital de Pediatria, Centro Medico Nacional Siglo XXI and Hospital General del Centro Medico Nacional La Raza, Mexico City. CP = Child-Pugh staging, $\mathrm{O}=$ Okuda staging. 
centers in Central (Mexico City, $\mathrm{n}=16$ ), West Mexico (Guadalajara, Jalisco, $\mathrm{n}=2$ ) and North Mexico (Monterrey, Nuevo Leon, $\mathrm{n}=2$ ). The age range of the adult patients was 16 to 87 years. In 7 studies, cirrhosis was present among liver biopsy or autopsy of HCC cases [20$25,31,33]$. In these cases, cirrhosis was attributed either to alcohol or viral hepatitis. In 6 studies, fibrolamellar HCC was diagnosed, especially among young patients $[24,28-30,34,36]$.

However, certain limitations were identified in this revision, such as, a lack of updated prospective studies, very few studies reported seroprevalence of viral markers and none of the studies performed nucleic acid testing (NAT) for viral hepatitis.

\subsection{Reported Incidence of HCC in Mexico}

Table 2 depicts the occurrence of HCC rates in either prospective or retrospective studies. Only one study estimated a prospective incidence of $0.25 \%$ from 10,025 new cancer patients [20]. In one retrospective study, mean annual incidence of $1.87 \%$ for HCC was estimated in a three year period among 282 liver disease patients [25]. In three autopsy series, the prevalence rate ranged from $0.19 \%$ to $0.59 \%$ [20-22]. As for HCC incidence adjusted by age, two retrospective studies carried out among pediatric patients ( $<15$ years of age) in Mexico City estimated an AAIR that ranged from 0.11 to $0.94 \times$ $10^{6}$ [26]. In another retrospective study, 17 cases out of 130 HCC cases were detected among patients younger than 40 years of age [29].

The demographic data presented in this study is representative of individuals that reside mainly in Mexico City and in a lesser extent from other regions of the country that attend tertiary hospitals to receive specialized health care. It may not reflect the total number of cases, since not all individuals can travel to their respective regional hospital for treatment nor does it cover most private institutions. Additionally, the lack of estimations based on
AAIR (by 100,000 inhabitants) in adults besides the incidence rate previously reported earlier $(0.22 / 100,000)$ [20] enabled us to compare the study groups. Despite these limitations, the data analyzed in this study relies on publications reporting histopathological confirmation of HCC cases and not overall liver cancer.

The low percentage of HCC cases is consistent with earlier observations reported from our locality [20], incidence rates reported in children and young adults [26,29], and statistical estimations based on international cancer mortality rates, including liver cancer, that indicate that Mexico has the lowest rate of HCC when compared to other regions of the world [38]. However, to fully support this conjecture, further updated prospective studies beginning at earlier stages of disease, i.e., in pre-cirrhotic or cirrhotic patients from different regions are required, together with a national-based incidence registry system for HCC cases.

\subsection{Relative Frequencies of HBV, HCV Infection and Alcohol Abuse in HCC Patients}

Table 3 depicts the facts regarding the relative frequency of the risk factors associated to HCC that was extracted from 6 studies [20,24,25,31-33]. Few studies reported seroprevalence of viral markers; from a total of 530 HCC cases, the seropositivity for HBsAg, anti-HCV, or both markers was $11 \%, 66 \%$ and $2.2 \%$ respectively. Alcohol abuse was reported in $6.6 \%$ of the cases, whereas other nonviral etiologies for HCC were reported in $14 \%$ of the studies.

In this present study, the primary risk factor was HCV infection as described previously [22], since the global ratio of HCC cases related to HCV compared to HBV was $6: 1$. In $11 \%$ of the HCC cases was HBsAg detected, however, HBV was not reported as the primary etiological agent of the 6 studies detailed in Table 3. To explain this high proportion of HCV-HCC related cases, we already have emphasized the discrepancy between the pre-

Table 2. Frequency rate reported for HCC cases in Mexico.

\begin{tabular}{lcccc}
\hline \multicolumn{1}{c}{ Time Interval Study design } & Study Period & Number of Study Cases & HCC cases $(n, \%)$ & Institution $^{*} /$ Reference \\
\hline 13-year period Retrospective study & $1953-66$ & 6558 autopsies & $30(0.45)$ & 1 , [21] \\
25-year period Retrospective study & $1965-89$ & 12,556 necropsies & $75(0.59)$ & 2 , [22] \\
10-year period Retrospective study & $1982-91$ & NR & $0.11 \times 10^{6 \text { (AAIR) }}$ & $9,[26]$ \\
10-year period Retrospective study & $1989-98$ & 2620 autopsies & $5(0.19)$ & 5 , [20] \\
20-year period Retrospective study & $1980-00$ & 282 chronic liver disease patients & $1.87 \% \%^{* *}$ & $4,[25]$ \\
3-year period Prospective study & $1996-98$ & with 3 year-follow up & $25(0.25)$ & $5,[20]$ \\
10-year period Prospective study & $1996-99$ & NR new cancer patients & $0.94 \times 10^{6 \text { (AAIR) }}$ & $9,[26]$
\end{tabular}

${ }^{*}=$ Institutions are provided in Table 1. ${ }^{* *}$ Mean annual incidence; NR = not reported. 
Table 3. Relative frequencies of risk factors related to HCC cases in Mexico.

\begin{tabular}{|c|c|c|c|c|c|c|c|}
\hline \multirow{2}{*}{ Time Interval (years) } & \multirow{2}{*}{ Sample size } & \multicolumn{5}{|c|}{ Prevalence $n(\%)$} & \multirow{2}{*}{ Reference } \\
\hline & & Anti-HCV ${ }^{+}$ & $H B s \mathrm{Ag}^{+}$ & $H B s \mathrm{Ag}^{+} / a n t i-H C V^{+}$ & Alcohol & Other $^{*}$ & \\
\hline $1980-00$ & 282 & $243(86)$ & 39 (14) & 0 & 0 & 0 & [25] \\
\hline 1985-93 & 21 & $4(19)$ & $4(19)$ & $2(10)$ & 0 & $11(52)$ & [24] \\
\hline 1990-02 & 71 & $43(61)$ & $6(8.0)$ & $10(14)$ & $7(10)$ & $5(7)$ & [32] \\
\hline 1991-00 & 89 & 37 (41.6) & $5(5.6)$ & 0 & $24(27)$ & $23(25.8)$ & [31] \\
\hline 1996-98 & 20 & $4(20)$ & $2(10)$ & 0 & $4(20)$ & $10(50)$ & [20] \\
\hline 2004-07 & 47 & $21(44)$ & NR & NR & NR & $26(56)$ & [33] \\
\hline Total & 530 & $352(66.0)$ & $56(11.0)$ & $12(2.2)$ & $35(6.6)$ & $75(14)$ & \\
\hline
\end{tabular}

Bold = preponderant cause, NR = not reported, *Other factors: Reference [24]: high serum levels of aflatoxins, [31]: criptogenic cirrhosis and minor causes of cirrhosis, [32] not specified, [20]: congenital $(n=2)$ and unidentified factors $(n=8)$, [33]: diabetes mellitus $(n=7)$, no risk factors $(n=7)$, missing data $(n=$ 12).

valence of viral hepatitis infections detected by immunoassays against highly sensitive molecular techniques $[12,13,39]$ and the validity of the immunological diagnostic techniques. For example, in patients with HBV infection, there is evidence that the major commercial immunoassays developed to detect HBsAg have a low specificity and sensitive for the predominant HBV genotype $H[13,14]$. Furthermore, this may also explain the steady state of HBsAg seroprevalence among the general Mexican population, and in blood donors [13]. This situation greatly hinders the possibility to detect HBV as a potential risk factor for HCC, together with the fact that NAT is not routinely performed for HBV or HCV in either clinical settings or blood banks nationwide. In contrast, the use of third-generation immunoassays for antiHCV have currently rendered less false-positive results that have enhanced the predictive value of this test for the diagnosis of HCV infection [40] and its potential etiological role in HCC cases. Moreover, it has been recently described, that $28 \%$ of the anti-HCV positive patients are HCV-RNA negative, a situation that could be related to the difference aforementioned [15].

On the other hand, hepatitis $\mathrm{C}$ seroprevalence and correspondence between viral load and viral genotype among primary care clients in Mexico is present, but the number of HCC cases does not correlate to the number of $\mathrm{HCV}$ infected patients as in other countries [16]. Unfortunately, HCV infection does not seem to be decreasing, even if the transfusion transmission has importantly decrease, other risk factors are increasing such as the nosocomial infection with infected material, the use of intravenous or intranasal drugs, imprisoned patients and homosexual patients have a higher risk of infection [16,41].

HBV genotypes are associated to the course and outcome of the further complications. For instance, HBV genotype $\mathrm{F}$ and its four subtypes [F1-F4] are endemic to America and are regionally distributed throughout the continent [42]. HBV genotype $\mathrm{F}$ has been associated to aggressive HCC cases in Native Alaska people [43] and to a poor long-term outcome in a cohort of chronic liver disease patients from Spain [44]. In these cases, other environmental factors different from those detected in Latin American may be involved [45].

Regarding HBV infection in Mexico, HBV genotype $\mathrm{H}$ is predominant among both the native [14] and mestizos as shown by registered migration events, DNA sequencing and phylogenetic analysis [39,46,47]. It has been estimated that at least 15 million people have been infected $[13,39,41]$ and among the native population, composed of another 10 to 12 million people, occult hepatitis B infection is common [14]. However, despite this situation, viral-related HCC incidence is low.

One reasonable explanation is the presence of a very low viral load [39] or a strong immune response that quickly lowers viral load. For example, we have recently described that native Nahuas serum samples that were HBsAg negative but HBV-DNA positive revealed differences in the serum levels of GRO-alpha, MCP-1 and -2 in individuals that were anti-HBc negative compared to those anti-HBc positive. These results indicate that, in these subjects, immune-ethnical mechanisms may be involved to suppress viral replication in occult HBVgenotype $\mathrm{H}$ infection [48]. Moreover, given that the processes involved in cell differentiation and the progression of HCC development is modulated through multiple growth factors and chemokines, this piece of information is suggestive of a coordinate cytokine production against HBV in Mexican individuals, which ultimately determines the degree of liver damage during viral infections. However, if the high incidence of occult hepatitis B infection turns out to be true for the majority 
of the native population, then, this entity may become a risk factor for HCC as demonstrated in other populations [49].

Altogether, these features differ from those reported in the high endemic areas of Asia, where HBV genotype B and genotype $\mathrm{C}$ carriers are prone to develop HCC [42, 50]. Further prospective studies are required to understand the HBV genotype H-Mexican host connection that could justify the low prevalence of HCC in Mexico compared to high-risk HCC populations.

Alcohol-induced cirrhosis is the second cause of death among the Mexican population between the ages of 15 to 64 years [17]. In fact, in Mexico, cirrhosis either due to alcohol or viruses is prevalent among young patients, mean age 44.6 years [51]. Additionally, we have described that alcoholic cirrhosis can be prevalent at young ages as 31.2 years (mean) [52], which is consistent with the fact that cirrhotic patients die prematurely of complications directly related to cirrhosis, such as upper gastrointestinal bleeding, hepatic encephalopathy, and infections. Thus, any evidence of early stage HCC might not be diagnosed or may not even be present at the time of death, due to the short period of progression of chronic liver disease.

Another aspect that occurs in Mexican patients is that, in the public institutions not all patients with chronic liver diseases or cirrhosis have an adequate screening for HCC, causing that many patients are not diagnosed opportunely. Interestingly, in this present study, $6.6 \%$ of the HCC cases were reported to relate to alcohol abuse and only a slightly higher proportion were related to viral hepatitis (Table 3). This finding is concordant with an earlier autopsy series study, in which the high incidence of cirrhosis did not correlate with the incidence of HCC [21]. To test this observation, the authors carried out a test that revealed that the main histopathological feature of the cirrhotic liver without HCC is a post-necrotic/micronodular type lesion attributed to a more benign regenerative process, whereas the cirrhotic scar in HCC is a post-hepatitic/macronodular type. These results highlight the relevance from an epidemiological standpoint that in spite of the high morbidity and mortality of liver cirrhosis, the prevalence of HCC in Mexico that should be expected is actually lower. Furthermore, it does not comply with the epidemiological pattern that suggests that the relative contribution of alcoholic cirrhosis to HCC should be higher in regions with low viral hepatitis prevalence [7].

\subsection{A Unique Protective Environmental Factor in Mexico}

Several studies have shown a strong association between dietary habits and human cancer incidence, including liver cancer [38,53,54]. Aflatoxin B1 is one of the most common mycotoxin that contaminates human foodstuffs such as corn, peanuts and cotton seeds [55]. The presence of this powerful hepatocarcinogen may overlap with chronic viral infections in developing countries of the Asian and African continents [56].

Regarding the Mexican population, we are the number one consumers of corn products in the world. The average consumption of "tortillas" is 300 - $325 \mathrm{~g} /$ person/day, which could account, for a daily exposure of serum aflatoxins of 14 - $85 \mathrm{ng} / \mathrm{kg}$ body weight [56]. These serum levels are equivalent to those that correlate with other populations living in regions that have an intermediate or a high incidence of HCC [18,19,21]. According to [56], the estimated annual HCC incidence with these serum aflatoxins levels among HBsAg negatives in Mexico could be $0.14-0.85 / 100,000$, whereas among the HBsAg positives, the incidence could rise to 4.20 - 25.5/100,000.

However, an intriguing paradox can be expressed due to the following evidence. Many traditional Mexican meals include maize (corn) tortillas and other similar products are prepared with a maize dough designated as "nixtamal", a word derived from the "nixtamalli", (nextli, ashes and tamalli, tamal) from the Aztec language, Nahuatl. The process of nixtamalization was developed by the Mesoamericans (in Mexico and Central America) in the pre-Columbian era and has been practiced without modifications ever since. To make the "nixtamal", dry corn grains are soaked and cooked in water added with alkaline lime either by $\mathrm{CaO}$ or $\mathrm{Ca}(\mathrm{OH})_{2}$, washed thoroughly and rinsed to remove the pericarp and then grinded by a stone or a mill [57].

It has been shown that nixtamalization can reduce significant amounts of aflatoxins in maize that would otherwise be present due to poor crop storage. [46] Additionally, in vitro studies have demonstrated that, with a $0.25 \% \mathrm{CaO}$ solution $[\mathrm{w} / \mathrm{v}]$ per kilo of maize, $96 \%$ of the toxin molecules in aflatoxin-contaminated nixtamal are inactivated [58]. Therefore, despite the exposure to potential high levels of aflatoxins, it seems likely that this nixtamalization process could be a specific environmental factor that protects Mexicans against HCC development. This is consistent with the fact that Asian and African individuals that consume aflatoxin-contaminated corn products without alkaline-lime treatment [56] and additionally reside in high prevalence regions for hepatitis B and C viruses have a higher risk of developing HCC [56].

In this present analysis, only one study reported serum alfatoxins with no clear association to HCC [24]. Further case-control trials are required to confirm the relationship between the use of alkaline-treated corn products and the low incidence of HCC in Mexico. 


\section{Reported Mortality Rates of HCC in Mexico}

Another way to estimate the burden of HCC on the Mexican population was to evaluate the mortality rates reported as the number of fatalities/100,000 inhabitants. These are available as a nationwide repository at the Secretariat of Health website

(http://sinais.salud.gob.mx/mortalidad/). However, neither the incidence nor prevalence rate of liver cancer cases, (specifically as HCC cases) is recollected on a population-based registry. Moreover, there are some limitations concerning the liver cancer mortality rates in Mexico, which gave rise to this research. First, information regarding liver cancer mortality before 1999 is considered unreliable [59]. Secondly, the following records registered an increase from 4.16 to 4.74 cases/100,000 inhabitants from 2000 to 2006 [59], and that the number of predicated liver cancer cases for the year 2050 may be over 77,000 [60] may not reflect the actual scenario of this malignancy in the Mexican population.

Our arguments are based on the discrepancy between the low percentage of HCC cases found in each study reviewed herein, contrary to what other authors could have overestimated $[60,61]$ This may be because all International Classification of Diseases codes for liver cancer (C22.0 - C22.9) were included in the mortality rate study. Additionally, the higher mortality rate may differ from the occurrence rate reviewed in this study, because HCC is not detected earlier. Consequently, it is diagnosed until relatively advanced stages of disease. In this situation, HCC may not be diagnosed with a histopathological confirmation that could allow distinguishing primary liver cancers from secondary metastasis of malignancy, thus leading to an equivocal registration of HCC on the death certificate. Yet another situation could be that diagnosis and certification of primary liver cancer may be influenced by increased surveillance of cirrhotic patients through different imaging techniques, which may lead to an apparent increase in the incidence of HCC [33,62].

Furthermore, the predication that the mortality rate due to liver cancer could increase in the next 50 years represents a theoretical point of view, which seems hard to accept, due to the low percentage of HCC cases and low prevalence of associated risk factors identified in the present study. However, it is important to state that obesity and obesity-related conditions such as type 2 diabetes mellitus, steatosis and nonalcoholic steatohepatitis are currently rising in Mexico (Secretariat of Health, 2010 Edition.). Altogether, given the evidence that we have shown regarding the early death of cirrhotic patients, it is more likely that these morbidities could have a more significant impact on the incidence and mortality for liver cirrhosis per se than in the development of HCC in Mexican patients.

Overall, despite these drawbacks, Mexico may still be consider of low incidence and low mortality rate for HCC cases compared to other countries worldwide [1,4], that may differ from one region to another. Further verification of the diagnosis criterion and estimates of HCC disease burden are required in order to avoid misleading statistics [63] that can cause serious diversions on the real scope of both the incidence and mortality rate of HCC.

\section{Conclusions}

In the last 50 years, the studies performed in Mexico have shown a very low incidence and/or mortality rate of HCC. These findings contrast from those reported in high endemic regions, such as Asia, where both, viral hepatitis and HCC are prevalent. One significant difference is the predominance of $\mathrm{HBV}$ genotype $\mathrm{H}$ in Mexico and $\mathrm{HBV} / \mathrm{B}$ and $\mathrm{C}$ in Asia. In Mexico, high endemic areas of HBV infection have also been detected, mainly among the native population; however, the disease seems to resolve very quickly, as a consequence of a prominent immunological response among the Mexican population.

Other factors that are in involved are that patients with liver cirrhosis die prematurely before that HCC can be detected. Furthermore, an environmental factor that may exert a protective effect against HCC, in spite of the high consumption of potentially aflatoxin-contaminated food products, is the neutralization of these substances by alkaline treatment. This study shows that genetic and environmental factors associated to HCC among the Mexican population are different from others worldwide.

\section{Acknowledgements}

We thank the Jalisco State Council of Science and Technology (COECYTJAL 2009-PS431) to AP and the National Council of Science and Technology (CONACYTFondo Sectorial S0008-2010-1-139085) to SR for financial support.

\section{REFERENCES}

[1] M. C. Kew, "Epidemiology of Chronic Hepatitis B Virus Infection, Hepatocellular Carcinoma, and Hepatitis B Virus-Induced Hepatocellular Carcinoma,” Pathologie Biologie, Vol. 58, No. 4, 2010, pp. 273-277. doi:10.1016/j.patbio.2010.01.005

[2] S. Franceschi and S. A. Raza, "Epidemiology and Prevention of Hepatocellular Carcinoma," Cancer Letters, Vol. 286, No. 1, 2009, pp. 5-8. doi:10.1016/j.canlet.2008.10.046

[3] P. P. Michielsen, S. M. Francque and J. L. van Dongen, 
"Viral Hepatitis and Hepatocellular Carcinoma," World Journal of Surgical Oncology, Vol. 3, 2005, p. 27. doi:10.1186/1477-7819-3-27

[4] S. A. Raza, G. M. Clifford and S. Franceschi, "Worldwide Variation in the Relative Importance of Hepatitis B and Hepatitis C Viruses in Hepatocellular Carcinoma: A Systematic Review," British Journal of Cancer, Vol. 96, No. 7, 2007, pp. 1127-1134. doi:10.1038/sj.bjc.6603649

[5] C. Bosetti, B. Cosetta, E, Negri, M. Colombo and C. La Vecchia, "Estimates of the Incidence and Prevalence of Hepatocellular Carcinoma in Italy in 2002 and Projections for the Years 2007 and 2012," Tumori, Vol. 95, No. 1, 2009, pp. 23-27.

[6] C. Neuveut, Y. Wie and M. A. Buendia. "Mechanisms of HBV-Related Hepatocarcinogenesis,” Journal of Hepatology, Vol. 52, No. 4, 2010, pp. 594-604. doi:10.1016/j.jhep.2009.10.033

[7] J. F. Perz, G. L. Armstrong, L. A. Farrinton Y. J. F. Hutin and B. P. Bell, "The Contributions of Hepatitis B Virus and Hepatitis C Virus Infections to Cirrhosis and Primary Liver Cancer Worldwide," Journal of Hepatology, Vol. 45, No. 4, 2006, pp. 529-538. doi:10.1016/j.jhep.2006.05.013

[8] J. Bruix, "Clinical Management of Hepatocellular Carcinoma,” Journal of Hepatology, Vol. 35, No. 3, 2001, pp. 421-430. doi:10.1016/S0168-8278(01)00130-1

[9] G. Fattovich, T. Stroffolini, I. Zagni and F. Donato, "Hepatocellular Carcinoma in Cirrhosis: Incidence and Risk Factors,” Gastroenterology, Vol. 127, No. 5, 2004, pp. S35-S50. doi:10.1053/j.gastro.2004.09.014

[10] M. C. Yu and J. M. Yuan, "Environmental Factors and Risk for Hepatocellular Carcinoma,” Gastroenterology, Vol. 127, No. 5, 2004, pp. S72-S78. doi:10.1016/j.gastro.2004.09.018

[11] C. P. Wild and P. C. Turner, "The Toxicology of Aflatoxins as a Basis for Public Health Decisions," Mutagenesis, Vol. 17, No. 6, 2002, pp. 471-481. doi:10.1093/mutage/17.6.471

[12] H. B. El-Serag, M. Lau, K. Eschbach, J. Davila and J. Goodwin, "Epidemiology of Hepatocellular Carcinoma in Hispanics in the United States," Archives of Internal Medicine, Vol. 167, No. 18, 2007, pp. 1983-1993. doi:10.1001/archinte.167.18.1983

[13] S. Roman, A. Panduro, Y. Aguilar-Gutierrez, M. Maldonado, M. V. Van-Dyck, E. Martinez-Lopez, et al., "A Low Steady HBsAg Seroprevalence Is Associated with a Low Incidence of HBV-Related Liver Cirrhosis and Hepatocellular Carcinoma in Mexico: A Systematic Review,” Hepatology International, Vol. 3, No. 2, 2009, pp. 343355. doi:10.1007/s12072-008-9115-9

[14] S. Roman, Y. Tanaka, A. Khan, F. Kurbanov, H. Kato, M. Mizokami, et al., "Occult Hepatitis B in the Genotype H-Infected Nahuas and Huichol Native Mexican Population,” Journal of Medical Virology, Vol. 82, No. 9, 2010, pp. 1527-1536. doi:10.1002/jmv.21846

[15] A. Panduro, S. Roman, A. Khan, Y. Tanaka, F. Kurbanov, E. Martinez-Lopez, et al., "Molecular Epidemiology of Hepatitis C Virus Genotypes in West Mexico,” Virus Re- search, Vol. 151, No. 1, 2010, pp. 19-25.

doi:10.1016/j.virusres.2010.03.009

[16] A. I. Burguete-García, C. J. Conde-González, R. Jiménez-Méndez, Y. Juárez-Díaz, E. Meda-Monzón, K. Torres-Poveda, et al., "Hepatitis C Seroprevalence and Correlation between Viral Load and Viral Genotype among Primary Care Clients in Mexico,” Salud Pública de México, Vol. 53, Suppl. 1, 2011, pp. S7-S12. doi:10.1590/S0036-36342011000700003

[17] “Anuario Estadístico de Morbilidad, 1984-2008," Secretaria de Salud de México (National Health Secretariat). http://www.dgepi.salud.gob.mx/anuario/html/anuarios.ht $\mathrm{ml}$

[18] S. García and N. Heredia, "Mycotoxins in Mexico: Epidemiology, Management and Control Strategies," Mycopatologica, Vol. 162, No. 3, 2006, pp. 255-264. doi:10.1007/s11046-006-0058-1

[19] D. Guzmán-de-Pena and J. J. Pena-Cabriales, “Regulatory Considerations of Aflatoxin Contamination of Food in Mexico," Revista Latinoamericana de Microbiologia, Vol. 47, No. 3-4, 2005, pp. 160-164.

[20] C. Vivas-Arceo, B. E. Bastidas-Ramirez and A. Panduro, "Hepatocellular Carcinoma Is Rarely Present in Western Mexico,” Hepatology Research, Vol. 16, No. 1, 1999, pp. 26-35. doi:10.1016/S1386-6346(99)00035-2

[21] E. Lopez-Corella, C. Ridaura-Sanz and J. AlboresSaavedra, "Primary Carcinoma of the Liver in Mexican Adults,” Cancer, Vol. 22, No. 3, 1968, pp. 678-685. doi:10.1002/1097-0142(196809)22:3<678::AID-CNCR28 20220326>3.0.CO;2-U

[22] T. Cortés-Espinosa, R. Mondragón-Sánchez, H. H. Andrade and R. Sánchez-Cisneros, "Hepatocellular Carcinoma and Hepatic Cirrhosis in Mexico: A 25 Year Necroscopy Review," Hepatogastroenterology, Vol. 44, No. 17, 1997, pp. 1401-1403.

[23] D. Garcia Compeán, F. J. Guzman de la Garza, L. E. M. Espinoza, R. V. Castillo, A. M. M. Flores, B. A. Fernández, et al., "Primary Liver Cancer. Its Epidemiological, Clinical and Biochemical Characteristics," Revista de Gastroenterología de México, Vol. 59, No. 1, 1994, pp. 17-22.

[24] Y. Soini, S. C. Chia, W. P. Bennett, J. D. Groopman, J. S. Wang, V. M. DeBenedetti, et al., "An Aflatoxin-Associated Mutational Hotspot at Codon 249 in the p53 Tumor Suppressor Gene Occurs in Hepatocellular Carcinomas from Mexico," Carcinogenesis, Vol. 17, No. 5, 1996, pp. 1007-1012. doi:10.1093/carcin/17.5.1007

[25] J. L. Rodríguez-Díaz, V. Rosas-Camargo, O. Vega-Vega, D. Morales-Espinosa, A. Méndez-Reguera, J. L. MartínezTlahuel, et al., "Clinical and Pathological Factors Associated with the Development of Hepatocellular Carcinoma in Patients with Hepatitis Virus Related Cirrhosis: A Long-Term Follow-Up Study,” Clinical Oncology (Royal College of Radiologists), Vol. 19, No. 3, 2007, pp. 197203. doi:10.1016/j.clon.2006.12.005

[26] J. M. Mejía-Arangure, O. Beutelspacher-Vázquez, S. JuárezOcaña, J. Vázquez-Langle, M. C. Martínez-García and A. Fajardo-Gutiérrez, "Incidence Trends of Hepatic Tumors in Childhood. Tendencia de la Incidencia de Los Tumores 
Hepáticos en la Infancia,” Salud Pública de México, Vol. 44, No. 2, 2002, pp. 100-107. doi:10.1590/S0036-36342002000200003

[27] R. Mondragón-Sánchez, F. J. Ochoa-Carrillo, J. M. RuizMolina, R. Herrera-Goepfer, L. F. Oñate-Ocaña and V. Aiello-Crocifoglio, "Hepatocellular Carcinoma. Experience at the Instituto Nacional de Cancerología,” Revista de Gastroenterología de México, Vol. 62, No. 1, 1997, pp. 34-40 [Spanish].

[28] J. Arista-Nasr, L. Gutiérrez-Villalobos, J. Nuncio, H. Maldonaldo and L. Bornstein-Quevedo, "Fibrolamellar Hepatocellular Carcinoma in Mexican Patients,” Pathology and Oncology Research, Vol. 8, No. 2, 2002, pp. 133-137. doi:10.1007/BF03033723

[29] E. Hernández-Castillo, R. Mondragón-Sánchez, A. L. Garduno-López, E. Gómez-Gómez, J. M. Ruiz-Molina, L. F. Oñate-Ocaña, et al., "Hepatocellular Carcinoma in the Youth. A Comparative Analysis with Hepatocellular Carcinoma in Adulthood,” Hepatogastroenterology Vol. 52, No. 63, 2005, pp. 903-907.

[30] L. E. Moreno-Luna, O. Arrieta, J. García-Leiva, B. Martínez, A. Torre, M. Uribe and E. León-Rodríguez, "Clinical and Pathological Factors Associated with Survival in Young Patients with Fibrolamellar Hepatocarcinoma,” BMC Cancer, Vol. 5, 2005, p. 142. doi:10.1186/1471-2407-5-142

[31] J. Meza-Junco, A. Montaño-Lozab and M. Candelaria, "Treatment Modalities in Patients with Hepatocellular Carcinoma: A Retrospective Series in a Single Institution in Mexico," "Modalidades de Tratamiento Para Pacientes con Carcinoma Hepatocelular: Una Serie Retrospectiva de Una Sola Institución en México,” Journal of Gastroenterology and Hepatology, Vol. 27, No. 1, 2004, pp. 1117. doi:10.1157/13056030

[32] R. Mondragón-Sánchez, A. L. Garduño-López, E. HernándezCastillo, E. Gómez-Gómez and J. M. Ruiz-Molina, "Hepatocellular Carcinoma and Hepatitis C in Mexico," Hepatogastroenterology, Vol. 52, No. 64, 2005, pp. 11591162.

[33] L. Ladrón de Guevara, P. Rojas-Macuil, X. SánchezChávez, A. Rossano-García, M. T. Gorraez-de-la-Mora, G. Cervantes-Sánchez, et al., "Hepatocellular Carcinoma: Epidemiological Profile from a Cohort of Federal Employees in Mexico,” Annals of Hepatology, Vol. 8, No. 3, 2009, pp. 212-219.

[34] J. L. Cervera, "Fibrolamellar Carcinoma in a Young Patient," Annals of Hepatologyl, Vol. 1, No. 4, 2002, pp. 197-198.

[35] A. Dardón, R. Corona and N. Méndez-Sánchez, "Hepatocellular Carcinoma Not Associated with Virus B and C and Alcohol,” Annals of Hepatology, Vol. 2, No. 1, 2003, p. 46.

[36] J. L. Valderrama-Landaeta, A. Güemez Meza, O. Albores Zúñiga and J. M. R. Molina, "Fibrolamellar Hepatocellular Carcinoma: A Case Presentation and Literature Review,”/ "Hepatocarcinoma Fibrolamelar: A Propósito de un Caso y Revisión de la Literatura,” Revista Médica de la EXtensión Portuguesa, Vol. 1, No. 1, 2007, pp. 24-28. http://www.saber.ula.ve/bitstream/123456789/24783/1/art iculo4.pdf

[37] J. Meza-Junco, A. J. Montano-Loza, B. Martínez-Benítez and E. Kimura-Hayama, "Hepatocellular Carcinoma in Patients with Autoimmune Liver Diseases: Two Case Reports and Literature Review,” Annals of Hepatology, Vol. 6, No. 2, 2007, pp. 122-126.

[38] C. Bosetti, T. Rodriguez, L. Chatenoud, P. Bertuccio, F. Levi, E. Negri, et al., "Trends in Cancer Mortality in Mexico, 1981-2007,” European Journal of Cancer Prevention, Vol. 20, No. 5, 2011, pp. 355-363. doi:10.1097/CEJ.0b013e32834653c9

[39] A. Panduro, M. Maldonado-Gonzalez, N. A. Fierro and S. Roman, "Distribution of Hepatitis B Virus Genotypes F and $\mathrm{H}$ in Mexico and Central America," Antiviral Therapy, 2013 (in Press).

[40] E. Chiquete and A. Panduro, "Low Prevalence of AntiHepatitis C Virus Antibodies in Mexico: A Systematic Review,” Intervirology, Vol. 50, No. 1, 2007, pp. 1-8. doi:10.1159/000096306

[41] A. Panduro, G. Escobedo-Meléndez, N. A. Fierro, B. Ruiz-Madrigal, E. A. Zepeda-Carrillo and S. Román, "Epidemiology of Viral Hepatitis in Mexico. Epidemiología de las Hepatitis Virales en México," Salud Pública de México, Vol. 53, Supl. 1, 2011, pp. S37-S45.

[42] F. H. Pujol, M. C. Navas, P. Hainaut and I. Chemin, "Worldwide Genetic Diversity of HBV Genotypes and Risk of Hepatocellular Carcinoma," Cancer Letters, Vol. 286, No. 1, 2009, pp. 80-88. doi:10.1016/j.canlet.2009.07.013

[43] S. E. Livingston, J. P. Simonetti, B. J. McMahon, L. R. Bulkow, K. J. Hurlburt, C. E. Homan, et al., "Hepatitis B Virus Genotypes in Alaska Native People with Hepatocellular Carcinoma: Preponderance of Genotype F," The Journal of Infectious Diseases, Vol. 195, No. 1, 2007, pp. 5-11. doi:10.1086/509894

[44] J. M. Sánchez-Tapias, J. Costa, A. Mas, M. Bruguera and J. Rodés, "Influence of Hepatitis B Virus Genotype on the Long-Term Outcome of Chronic Hepatitis B in Western Patients," Gastroenterology, Vol. 123, No. 6, 2002, pp. 1848-1856. doi:10.1053/gast.2002.37041

[45] F. Pujol, S. Roman, A. Panduro, M. C. Navas and E. Lampe, "Hepatocellular Carcinoma in Latin America," In: I. Chemin, Ed., Hepatocellular Carcinoma: A Global Challenge, 1st Edition, Nova Science Publishers Inc., New York, 2011, pp. 55-68.

[46] L. V. Sanchez, M. Maldonado, B. E. Bastidas-Ramirez, H. Norder and A. Panduro, "Genotypes and S-Gene Variability of Mexican Hepatitis B Virus Strains,” Journal of Medical Virology, Vol. 68, No. 1, 2002, pp. 24-32. doi:10.1002/jmv.10166

[47] L. V. Sánchez, Y. Tanaka, M. Maldonado, M. Mizokami and A. Panduro, "Difference of Hepatitis B Virus Genotype Distribution in Two Groups of Mexican Patients with Different Risk Factors. High Prevalence of Genotype $\mathrm{H}$ and G,” Intervirology, Vol. 50, No. 1, 2007, pp. 9-15. doi:10.1159/000096307 
[48] N. A. Fierro, S. Roman, M. Realpe, Z. Hernandez-Nazara, E. A. Zepeda-Carrillo and A. Panduro, "Multiple Cytokine Expression Profiles Reveal Immune-Based Differences in Occult Hepatitis B Genotype H-Infected Mexican Nahua Patients,” Memórias do Instituto Oswaldo Cruz, Vol. 106, No. 8, 2011, pp. 1007-1013.

[49] F. B. Hollinger and G. Sood, "Occult Hepatitis B Virus Infection: A Covert Operation,” Journal of Viral Hepatitis, Vol. 17, No. 1, 2010, pp. 1-15. doi:10.1111/j.1365-2893.2009.01245.X

[50] H. L. Chan, M. L. Wong, A. Y. Hui, L. C. Hung, F. K. Chan and J. J. Sung, "Hepatitis B Virus Genotype C Takes a More Aggressive Disease Course than Hepatitis B Virus Genotype B in Hepatitis B e Antigen-Positive Patients," Journal of Clinical Microbiology, Vol. 41, No. 3, 2003, pp. 1277-1279. doi:10.1128/JCM.41.3.1277-1279.2003

[51] Z. H. Hernandez-Nazara, B. Ruiz-Madrigal, E. Martinez-Lopez, S. Roman and A. Panduro, "Association of the E2 Allele of ApoE Gene to Hypertriglyceridemia and to Early-Onset of Alcoholic Cirrhosis," Alcoholism: Clinical and Experimental Research, Vol. 32, No. 3, 2008, pp. 1-8. doi:10.1111/j.15300277.2007.00607.x

[52] B. E. Bastidas-Ramirez, P. Nuno-Gonzalez, C. Vivas Arceo, L. V. Sanchez-Orozco and A. Panduro, "Albumin mRNA in Peripheral White Blood Cells of Cirrhotic Patients with a Superimposed Alcoholic Hepatitis Is Associated to Fatal Outcome,” Hepatology Research, Vol. 24, No. 3, 2002, pp. 265-274. doi:10.1016/S1386-6346(02)00109-2

[53] S. C. Chuang, C. La Vecchia and P. Boffetta, "Liver Cancer: Descriptive Epidemiology and Risk Factors Other than HBV and HCV Infection," Cancer Letters, Vol. 286, No. 1, 2009, pp. 9-14. doi:10.1016/j.canlet.2008.10.040

[54] T. J. Key, A. Schatzkin, W. C. Willett, N. E. Allen, E. A. Spencer and R. C. Travis, "Diet, Nutrition and the Prevention of Cancer," Public Health Nutrition, Vol. 7, No. 1A, 2004, pp. 187-200. doi:10.1079/PHN2003588

[55] T. W. Kensler, B. D. Roebuck, G. N. Wogan and J. D. Groopman, "Aflatoxin: A 50-Year Odyssey of Mechanistic and Translational Toxicology,” Toxicological Sciences, Vol. 120, Suppl. 1, 2011, pp. S28-S48.

\section{doi:10.1093/toxsci/kfq283}

[56] Y. Liu and F. Wu, "Global Burden of Aflatoxin-Induced Hepatocellular Carcinoma: A Risk Assessment,” Environmental Health Perspectives, Vol. 118, No. 6, 2010, pp. 818-824. doi:10.1289/ehp.0901388

[57] C. Wacher, "Nixtamalization, A Mesoamerican Technology to Process Maize at Small Scale with Great Potential for Improving the Nutritional Quality of Maize Based Foods," 2nd International Workshop. Food-Based Approaches for a Healthy Nutrition, Ouagadougou, 23 November 2003, pp. 1-10.

http://www.univ-ouaga.bf/conferences/fn2ouaa2003/abstr acts/0715_FP_O4_Mexico_Wacher.pdf

[58] G. L. Anguiano-Ruvalcaba, A. V. Vargas-Cortina and D. G.-D. Peña, "Inactivation of Aflatoxin B1 and Aflatoxicol through Traditional 'Nixtamalización' of Corn and Their Regeneration by Acidification of Corn Dough,” Salud Pública de México, Vol. 47, No. 5, 2005, pp. 369-375. doi:10.1590/S0036-36342005000500007

[59] M. Malvezzi, C. Bosetti, L. Chatenoud, T. Rodrıguez, F. Levi, E. Negri, et al., "Trends in Cancer Mortality in Mexico, 1970-1999,” Annals of Oncology, Vol. 15, No. 11, 2004, pp. 1712-1718. doi:10.1093/annonc/mdh424

[60] N. Méndez-Sánchez, A. R. Villa, N. C. Chávez-Tapia, G. Ponciano-Rodríguez, P. Almeda-Valdés, D. González, et al., "Trends in Liver Disease Prevalence in Mexico from 2005 to 2050 through Mortality Data," Annals of Hepatology, Vol. 4, No. 1, 2005, pp. 52-55.

[61] N. Méndez-Sánchez, A. R. Villa, G. Vázquez-Elizondo, G. Ponciano-Rodríguez and M. Uribe, "Mortality Trends for Liver Cancer in Mexico from 2000 to 2006," Annals of Hepatology, Vol. 7, No. 3, 2008, pp. 226-229.

[62] A. P. Venook, C. Papandreou, J. Furuse and L. L. de Guevara, "The Incidence and Epidemiology of Hepatocellular Carcinoma: A Global and Regional Perspective,” The Oncologist, Vol. 15, Suppl. 4, 2010, pp. 5-13. doi:10.1634/theoncologist.2010-S4-05

[63] E. Fassio, S. Diaz, C. Santa, M. E. Reig, Y. Martínez Artola, A. Alves de Mattos, et al., "Multicenter Group for Study of Hepatocarcinoma in Latin America, "Etiology of Hepatocellular Carcinoma in Latin America: A Prospective, Multicenter, International Study," Annals of Hepatology, Vol. 9, No. 1, 2010, pp. 63-69. 